\title{
Recent Advances in Understanding Plant Heterosis
}

\author{
Shouqian Feng, Xiaoliu Chen, Shujing Wu, Xuesen Chen* \\ The State Key Laboratory of Crop Biology; National Research Center for Apple Engineering and Technology, \\ College of Horticulture Science and Engineering, Shandong Agricultural University, Tai'an, China \\ Email: ${ }^{*}$ chenxs@sdau.edu.cn
}

Received 16 July 2015; accepted 20 September 2015; published 23 September 2015

Copyright (C) 2015 by authors and Scientific Research Publishing Inc.

This work is licensed under the Creative Commons Attribution International License (CC BY).

http://creativecommons.org/licenses/by/4.0/

c) (i) Open Access

\begin{abstract}
Although heterosis is widely utilized in crop production, its genetic and molecular basis is still elusive. It is arguably that heterosis arises in crosses between genetically and/or epigenetically distinct individuals. Various genetic models have been proposed to explain heterosis, such as dominance and overdominance hypothesis. With the recent advancements in functional genomics, epigenetics, transcriptomics, proteomics, and metabolomics-related technologies, systems-level approaches have been adopted to understand the molecular basis of heterosis. In this review, we gather a brief account of findings from various studies in order to better understand the genetic and molecular basis of heterosis.
\end{abstract}

\section{Keywords}

\section{Heterosis, Genetic Factor, Epigenetic Factor}

\section{General View of Heterosis}

Heterosis is a common phenomenon in many plants. Heterosis is formed by crossing different strains or varieties. Heterosis refers to the super performance of a hybrid exhibiting increased biomass, size, yield, growth rate, or fertility relative to its parents [1]. Joseph Koelreuter (1776) described that some plant hybrids displayed superior growth over their parents [2]. In 1876, Charles Darwin concluded that "the crossed plants when fully grown were plainly taller and more vigorous than the self-fertilised ones". Then he observed the growth patterns in more than 60 plant species [3]. The phenomenon was rediscovered by George H. Shull, and he firstly introduced the term heterosis in 1914 [4]. Since then, heterosis has been widely utilized in crop breeding, especially in maize. In the late 1990 s, it was estimated that $65 \%$ of the worldwide maize (Zea mays) area was planted as hybrids,

"Corresponding author. 
and the yield of maize had increased six fold since the use of hybrids started in the 1930s [5]. The economic importance of heterosis has led to extensive research to understand its basis. However, the genetic and molecular mechanisms for heterosis are still poorly understood. In this review, we present a brief account of findings in various heterosis studies (Table 1 ).

\section{Genetic Analysis of Heterosis}

Although the genetic basis for heterosis has been studied for over a century and several hypotheses have been advanced to explain the phenomenon, less progress has been made for the genetic basis of heterosis. Conventionally, dominance and overdominance were the two most prominent genetic hypotheses for heterosis [6]. The dominance hypothesis proposes that complementation of corresponding deleterious alleles lead to heterosis in hybrids [7] [8]. The overdominance hypothesis proposes that heterozygous allelic interactions result in heterosis in hybrids [1]. In summary, both the two genetic hypotheses describe genetic differences between hybrids and inbred lines. However, it is difficult to directly associate the favorable alleles that "dominant" and "overdominant” predict with the phenotypic traits in crop breeding (including maize) [9].

\section{Transcriptomic and Proteomic Analysis of Heterosis}

Various transcriptomic analyses have been carried out to explore the gene expression changes between hybrid and its parents to correlate the changes to heterosis. Based on the modes of gene action in the hybrid, the genes have mainly been classified as additive, dominance and over-dominance (non-additive) expression patterns [6]. Additive expression represents mid-parental expression patterns in the hybrid, whereas the dominance model suggests both low and high parent-like expression. In the case of over-dominance, the gene expression level in hybrid is either higher or lower than the level in parent. Various aspects of plant development and different organs have been analyzed at the transcriptome level. In summary, there is no uniform global expression detected in these studies.

Several studies indicated that non-additive gene expression was prevalent between parent and hybrid [10][13], while additive gene expression was detected in other studies [14] [15]. In addition, a similar number of genes followed additive and non-additive expression model was also observed [16]. Interestingly, of the two heterotic rice hybrid, non-additive gene expression was prevalent in one hybrid, while additive gene expression in another at the younger stages of development [11]. Although the modes of gene expression vary from different studies, the global trends are similar. For example, heterosis is a genome-wide phenomenon involves global

Table 1. Heterosis related studies.

\begin{tabular}{|c|c|c|}
\hline Scope of the research & Results or factors related to heterosis & References \\
\hline Genetics & Dominance & {$[7][8]$} \\
\hline Genetics & Over-dominance & {$[1]$} \\
\hline Transcriptomics & $\begin{array}{l}\text { Global expression } \\
\text { trend (additive, non-additive and dominance) }\end{array}$ & {$[11]-[13][16]$} \\
\hline Transcriptomics & Genomic imprinting & {$[10]$} \\
\hline Transcriptomics & Parent-of-origin effects & {$[19][20][21]$} \\
\hline Transcriptomics & Dosage-sensitive factors & {$[22]$} \\
\hline Transcriptomics & Altered expression of circadian and flowering genes & {$[25]$} \\
\hline Proteomics & $\begin{array}{l}\text { Global expression } \\
\text { trend (additive and non-additive) }\end{array}$ & {$[27]$} \\
\hline Proteomics & Altered expression of isoforms and modifications proteins & {$[28]$} \\
\hline Epigenetics & DNA methylation & {$[18][23][24]$} \\
\hline Epigenetics & Small RNAs & {$[17]$} \\
\hline Energies & Energy utilization efficiency & [31] \\
\hline
\end{tabular}


changes in gene expression. More significant expression differences are found in the related species than those within species [6].

Allelic expression variation was further detected in many plant hybrids, such as maize and rice [17] [18]. Some genes in maize showed maternal or paternal like expression patterns, which were suggested to be associated with genomic imprinting [10]. Whereas in some studies, the minimal parent-of-origin effects on allelespecific expression were also detected [19]-[21].

A recent study gives a mechanism that allelic diversity is sensitive to dosage-sensitive factors [22]. Besides genetic factors, epigenetic factor was also suggested to play a potential role in allelic expression in hybrids [17] [18]. Recently, small RNA levels were measured in inbreds and hybrids. The differential expression patterns of small RNAs have been linked to heterosis [23] [24]. Importantly, several genes including circadian clock gene CCA1 and flowering gene SINGLE FLOWER TRUSS have been found to play an important role in heterosis [25].

The expression of proteins in inbreds and hybrids has been measured in various studies, some of which indicated a strong correlation between heterosis and protein patterns [26] [27]. Proteomic analysis in maize and rice showed that more frequency of non-additive protein expressional variation than non-additive gene expressional variation in hybrids [27] [28]. Recently, the expression level of protein was compared using heterotic and non-heterotic maize hybrids. Interestingly, the differential expressions of proteins detected in heterotic hybrids were mainly involved in stress response, protein and carbon metabolism. In addition, the degree of heterosis was suggested to be linked to the frequency of protein isoforms and modifications [28].

Although the different modes of gene action as well as protein expression patterns were observed in hybrids and they supported the genetic models of dominance and over-dominance, the molecular basis of heterosis is still largely unknown.

\section{Epigenetics Analysis of Heterosis}

Combination of diverged maternal and paternal genomes in the same nucleus may lead to genomic instability, epigenetic and gene expression changes, which ultimately caused the changes of phenotype in hybrid. In the past few years, various studies have been carried out to find the role of epigenetics in heterosis.

Genome-wide methylation, sRNAs expression, gene expression and physiological index have been analyzed comprehensively in both hybrid and its parents. The variations of DNA methylation and sRNAs were observed between parents and their progeny. A recent study by Shen et al. (2012) found that hybrids had increased cytosine methylation compared with the parents [24]. Contrast to the higher methylation levels, more down-regulated genes were existed in the hybrids than the parental lines. The down-regulated genes including the circadian clock genes CCA1, $L H Y$, have been shown to be involved in heterosis previously. In consistent with the study by Shen et al. (2012), Greaves et al. (2012) also found altered methylomes between hybrid and its parents in Arabiodposis [23]. In both studies changes occur most frequently at loci where parental methylation levels are markedly different.

A recent study by Chodavarapu et al. (2012) found that regions of altered methylation are often correlated with changes in sRNA levels [18]. Using Arabidposis, Greaves et al. (2012) and Shen et al. (2012) also found a close relationship between DNA methylation and sRNA [23] [24]. Interestingly, research by Shen et al. (2012) found that the growth vigor was compromised in the F1 hybrids of hen1 (RNA methyltransferase, HUA ENHANCER1) mutants, which further supported the notion that sRNAs play a role in heterosis, perhaps by guiding methylation of DNA via the RNA-directed DNA methylation pathway [24].

Differential expression patterns of small RNAs were observed in rice, wheat and tomato hybrids recently [17]. For example, in rice hybrids sRNAs showed more down-regulated than up-regulated. Previously, various studies have proved that sRNAs play an important role in gene regulation and genome integrity maintaining [29] [30]. It is possible that, the changes in sRNAs profiling could result in the expression patterns of gene that they control in hybrids, which might be related with the phenotype of the hybrids.

\section{Energy Model Proposed for Heterosis}

A recent energy model was proposed by Goff (2011) to explain differences in growth and yield between inbreds and hybrids [31]. According to this model, allele-specific gene expression is linked to protein folding and stability, and helps conserve energy and allows faster cell division. It is possible that allelic choice available in hybr- 
ids but not inbreds provides the opportunity for hybrids to express the favorable allele and use energy efficiency to accelerate crop improvement.

Heterosis is a common phenomenon in maize, rice and other species [6]. It is likely that a common biological mechanism underlying heterosis is existed in a wide variety of different species. Dominance and overdominance models have been proposed to explain single trait heterosis [32]. At gene expression level, both additive and non-additive mode of differential gene actions have been shown to be involved in the manifestation of heterosis [11] [14]-[16]. Genes influencing heterosis could be affected by genomic dosage [22]. Recently, mounting evidences of the epigenetic machinery was provided to explain heterosis [18] [23] [24] [33] [34]. Quantitative trait locus (QTL) mapping studies indicated many QTLs associated with specific heterosis traits [35]-[37]. Circadian clocks affected many traits in hybrids [6]. Energy-use efficiency likely plays an important role in heterosis [31]. Taken together, it is likely that the combination of many mechanisms across many genes accounts for the complex heterosis traits (Figure 1).

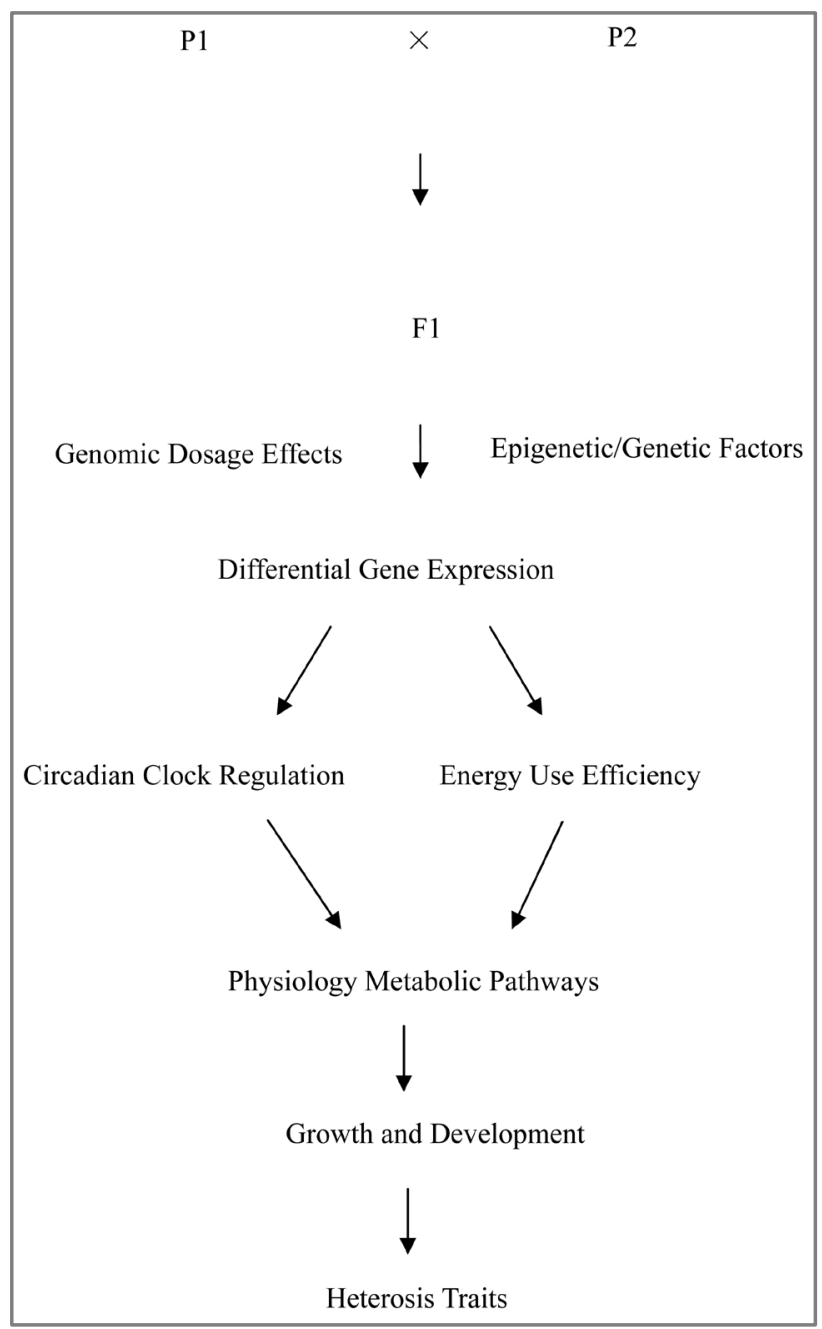

Figure 1. Possible mechanisms underlying heterosis. In the hybrids (F1), differential gene expression was induced when parent 1 (P1) and parent 2 (P2) genomes was mixed, mainly caused by epigenetic and genetic factors, and could be affected by genomic dosage. These expression changes may affect some major regulatory pathways including circadian clock pathway and energy regulatory pathway. A number of downstream physiology metabolic pathways could be affected, which ultimately affect various aspects of growth and development. 
To date, there are still many things that are not clear but with promising for future breakthrough in uncovering the heterosis. First, what is the relationship between genome combination and gene activity at a single gene level? It is known that the differential expression of a large number of genes is emerged when two different genomes come together in a hybrid. Do all these changed transcriptome in hybrid have biological functions? What proportion of the altered hybrid transcriptome could have a major influence on heterosis besides the circadian clock genes? What factors affect on the variable profile of these key genes, mechanisms? Second, how to choose the best combinations of parents for producing "super hybrids" to meet the growing demand in food and biofuels? As we known, the degree of heterosis is proportional to the genetic differences in two parental strains. However, many interspecific hybrids especially distant hybrids cannot survive, which cause hybrid incompatibility. A better understanding of the mechanism for hybrid vigor will help us effectively select the best combinations of parents for the predicting breeding goal, such as the increased production of seeds, fruits and metabolites.

\section{Acknowledgements}

This work was supported by National Natural Science Foundation of China (31201593).

\section{References}

[1] Shull, G.H. (1908) The Composition of a Field of Maize. Journal of Heredity, 4, 296-301. http://dx.doi.org/10.1093/jhered/os-4.1.296

[2] Reed, H.S. (1942) A Short History of the Plant Sciences. Ronald Proess Co., Waltham, 323.

[3] Darwin, C.R. (1876) The Effects of Cross-and Self-Fertilisation in the Vegetable Kingdom. John Murry, London.

[4] Shull, G.H. (1948) What Is “Heterosis”? Genetics, 33, 439-446.

[5] Duvick, J. (2001) Prospects for Reducing Fumonisin Contamination of Maize through Genetic Modification. Environmental Health Perspectives, 109, 337-342.

[6] Chen, Z.J. (2010) Molecular Mechanisms of Polyploidy and Hybrid Vigor. Trends in Plant Science, 15, 57-71. http://dx.doi.org/10.1016/j.tplants.2009.12.003

[7] Jones, D.F. (1917) Dominance of Linked Factors as a Means of Accounting for Heterosis. Genetics, 2, 466-479. http://dx.doi.org/10.1073/pnas.3.4.310

[8] Troyer, A.F. (2006) Adaptedness and Heterosis in Corn and Mule Hybrids. Crop Science, 46, 528-543. http://dx.doi.org/10.2135/cropsci2005.0065

[9] Duvick, D.N. and Cassman, K.G. (1999) Post-Green Revolution Trends in Yield Potential of Temperate Maize in the North-Central United States. Crop Science, 39, 1622-1630. http://dx.doi.org/10.2135/cropsci1999.3961622x

[10] Guo M., Mary A. Rupe, M.A., Danilevskaya, O.N., Yang, X.F. and Hu, Z.H. (2003) Genome-Wide mRNA Profiling Reveals Heterochronic Allelic Variation and a New Imprinted Gene in Hybrid Maize Endosperm. The Plant Journal, 36, 30-44. http://dx.doi.org/10.1046/j.1365-313X.2003.01852.x

[11] Zhang, H.Y., He, L., Chen, L.B., Li, L., Liang, M.Z., et al. (2008) A Genome-Wide Transcription Analysis Reveals a Close Correlation of Promoter INDEL Polymorphism and Heterotic Gene Expression in Rice Hybrids. Molecular Plant, 1, 720-731. http://dx.doi.org/10.1093/mp/ssn022

[12] Fujimoto, R., Taylor, J.M., Shirasawa, S., Peacock, W.J. and Dennis, E.S. (2012) Heterosis of Arabidopsis Hybrids between C24 and Col Is Associated with Increased Photosynthesis Capacity. Proceedings of the National Academy of Sciences, 109, 7109-7114. http://dx.doi.org/10.1073/pnas.1204464109

[13] Meyer, R.C., Witucka-Wall, H., Becher, M., Blacha, A., Boudichevskaia, A., et al. (2012) Heterosis Manifestation during Early Arabidopsis Seedling Development Is Characterized by Intermediate Gene Expression and Enhanced Metabolic Activity in the Hybrids. The Plant Journal, 71, 669-683. http://dx.doi.org/10.1111/j.1365-313X.2012.05021.x

[14] Huang, Y., Zhang, L., Zhang, J., Yuan, D., Xu, C., et al. (2006) Heterosis and Polymorphisms of Gene Expression in an Elite Rice Hybrid as Revealed by a Microarray Analysis of 9198 Unique ESTs. Plant Molecular Biology, 62, 579591. http://dx.doi.org/10.1007/s11103-006-9040-z

[15] Swanson-Wagner, R.A., Jia, Y., DeCook, R., Borsuk, L.A., Nettleton, D., et al. (2006) All Possible Modes of Gene Action Are Observed in a Global Comparison of Gene Expression in a Maize F1 Hybrid and Its Inbred Parents. Proceedings of the National Academy of Sciences, 103, 6805-6810. http://dx.doi.org/10.1073/pnas.0510430103

[16] Guo, M., Rupe, M.A., Yang, X.F., Crasta, O., Zinselmeier, C., et al. (2006) Genome-Wide Transcript Analysis of Maize Hybrids: Allelic Additive Gene Expression and Yield Heterosis. Theoretical and Applied Genetics, 113, 831-845. http://dx.doi.org/10.1007/s00122-006-0335-x 
[17] He, G., Zhu, X.P., Elling, A.A., Chen, L.B., Wang, X.F., et al. (2010) Global Epigenetic and Transcriptional Trends among Two Rice Subspecies and Their Reciprocal Hybrids. The Plant Cell, 22, 17-33. http://dx.doi.org/10.1105/tpc.109.072041

[18] Chodavarapu, R.K., Feng, S., Ding, B., Stacey, S.A., Lopez, D., Jia, Y., Wang, G.L., Meyers, B.C., Jacobsen, S.E. and Pellegrini, M. (2012) Transcriptome and Methylome Interactions in Rice Hybrids. Proceedings of the National Academy of Sciences, 109, 12040-12045. http://dx.doi.org/10.1073/pnas.1209297109

[19] Guo, M., Rupe, M.A., Zinselmeier, C., Habben, J., Bowen, B.A. and Smith, O.S. (2004) Allelic Variation of Gene Expression in Maize Hybrids. The Plant Cell, 16, 1707-1716. http://dx.doi.org/10.1105/tpc.022087

[20] Stupar, R.M. and Springer, N.M. (2006) Cis-Transcriptional Variation in Maize Inbred Lines $\mathrm{B}_{73}$ and $\mathrm{Mo}_{17}$ Leads to Additive Expression Patterns in the $\mathrm{F}_{1}$ Hybrid. Genetics, 173, 2199-2210. http://dx.doi.org/10.1534/genetics.106.060699

[21] Baranwal, V.K., Mikkilineni, V., Zehr, U.B., Tyagi, A.K. and Kapoor, S. (2012) Heterosis: Emerging Ideas about Hybrid Vigour. Journal of Experimental Botany, 63, 6309-6314. http://dx.doi.org/10.1093/jxb/ers291

[22] Yao, H., Gray, A.D., Auger, D.L. and Birchler, J.A. (2013) Genomic Dosage Effects on Heterosis in Triploid Maize. Proceedings of the National Academy of Sciences, 110, 2665-2669. http://dx.doi.org/10.1073/pnas.1221966110

[23] Greaves, I.K., Groszmann, M., Ying, H., Taylor, J.M., Peacock, W.J. and Dennis, E.S. (2012) Trans Chromosomal Methylation in Arabidopsis Hybrids. Proceedings of the National Academy of Sciences, 109, 3570-3575. http://dx.doi.org/10.1073/pnas.1201043109

[24] Shen, H., He, H., Li, J., Chen, W., Wang, X., Guo, L., Peng, Z., He, G., Zhong, S., Qi, Y., Terzaghi, W. and Deng, X.W. (2012) Genome-Wide Analysis of DNA Methylation and Gene Expression Changes in Two Arabidopsis Ecotypes and Their Reciprocal Hybrids. The Plant Cell, 24, 875-892. http://dx.doi.org/10.1105/tpc.111.094870

[25] Ni, Z., Kim, E.D., Lackey, E., Liu, J., Zhang, Y., Sun, Q. and Chen, Z.J. (2009) Altered Circadian Rhythms Regulate Growth Vigor in Hybrids and Allopoloids. Nature, 457, 327-331. http://dx.doi.org/10.1038/nature07523

[26] Hoecher, N., Lamkemeyer, T., Sarholz, B., Paschold, A., Fladerer, C., et al. (2008) Analysis of Non-Additive Protein Accumulation in Young Primary Roots of a Maize (Zea mays L.) $\mathrm{F}_{1}$-Hybrid Compared to Its Parental Inbred Lines. Proteomics, 8, 3882-3894. http://dx.doi.org/10.1002/pmic.200800023

[27] Wang, W., Meng, B., Ge, X., Song, X., Yang, Y., et al. (2008) Proteomic Profiling of Rice Embryos from a Hybrid Rice Cultivar and Its Parental Lines. Proteomics, 8, 4808-4821. http://dx.doi.org/10.1002/pmic.200701164

[28] Dahal, D., Mooney, B.P. and Newton, K.J. (2012) Specific Changes in Total and Mitochondrial Proteomes Are Associated with Higher Levels of Heterosis in Maize Hybrids. The Plant Journal, 72, 70-83. http://dx.doi.org/10.1111/j.1365-313X.2012.05056.x

[29] He, L. and Hannon, G.J. (2004) Micro RNAs: Small RNAs with a Big Role in Gene Regulation. Nature Reviews Genetics, 5, 522-531. http://dx.doi.org/10.1038/nrg1379

[30] Ng, D.W., Lu, J. and Chen, Z.J. (2012) Big Roles for Small RNAs in Polyploidy, Hybrid Vigor, and Hybrid Incompatibility. Current Opinion in Plant Biology, 15, 154-161. http://dx.doi.org/10.1016/j.pbi.2012.01.007

[31] Goff, S.A. (2011) A Unifying Theory for General Multigenic Heterosis: Energy efficiency, Protein Metabolism, and Implications for Molecular Breeding. New Phytologist, 189, 923-937. http://dx.doi.org/10.1111/j.1469-8137.2010.03574.x

[32] Kaeppler, S. (2012) Heterosis: Many Genes, Many Mechanisms-End the Search for an Undiscovered Unifying Theory. ISRN Botany, 2012, Article ID: 682824. http://dx.doi.org/10.5402/2012/682824

[33] Barber, W.T., Zhang, W., Win, H., Varala, K.K., Dorweiler, J.E., Hudson, M.E. and Moose, S.P. (2012) Repeat Associated Small RNAs Vary among Parents and Following Hybridization in Maize. Proceedings of the National Academy of Sciences of the United States of America, 109, 10444-10449. http://dx.doi.org/10.1073/pnas.1202073109

[34] Shivaprasad, P.V., Dunn, R.M., Santos, B.A., Bassett, A. and Baulcombe, D.C. (2012) Extraordinary Transgressive Phenotypes of Hybrid Tomato Are Influenced by Epigenetics and Small Silencing RNAs. EMBO Journal, 31, 257-266. http://dx.doi.org/10.1038/emboj.2011.458

[35] Frascaroli, E., Canè, M.A., Landi, P., Pea, G., Gianfranceschi, L., Villa, M., Morgante, M. and Pè, M.E. (2007) Classical Genetic and Quantitative Trait Loci Analyses of Heterosis in a Maize Hybrid between Two Elite Inbred Lines. Genetics, 176, 625-644. http://dx.doi.org/10.1534/genetics.106.064493

[36] Radoev, M., Becker, H.C. and Ecke, W. (2008) Genetic Analysis of Heterosis for Yield and Yield Components in Rapeseed (Brassica napus L.) by Quantitative Trait Locus Mapping. Genetics, 179, 1547-1558. http://dx.doi.org/10.1534/genetics.108.089680

[37] Krieger, U., Lippman, Z.B. and Zamir, D. (2010) The Flowering Gene SINGLE FLOWER TRUSS Drives Heterosis for Yield in Tomato. Nature Genetics, 42, 459-463. http://dx.doi.org/10.1038/ng.550 